\title{
The influence of acorn flour on rheological properties of gluten-free dough and physical characteristics of the bread
}

\author{
Jarosław Korus • Mariusz Witczak • \\ Rafał Ziobro $\cdot$ Lesław Juszczak
}

Received: 15 October 2014 / Revised: 9 January 2015 / Accepted: 11 January 2015 / Published online: 21 January 2015

(C) The Author(s) 2015. This article is published with open access at Springerlink.com

\begin{abstract}
Manufacture of gluten-free products requires the use of preselected raw materials. The number of such ingredients is limited; therefore, the portfolio of glutenfree bread is less variable and attractive in terms of their appearance, taste and nutritional value in comparison with traditional bread. The aim of the study was to apply debittered acorn flour as a natural nutritional enrichment of gluten-free bakery products and to check its effects on rheological properties of the dough and quality and staling of the bread. The analysis of rheological properties of gluten-free dough supplemented with acorn flour exhibited significant increase in the moduli $G^{\prime}$ and $G^{\prime \prime}$ and a decrease in phase shift tangent, which denotes firming of dough structure. Introduction of limited amounts of acorn flour caused an increase in bread volume and improved crumb characteristics. In consequence of a diminished starch retrogradation, the respective loaves exhibited slower staling. Bread supplemented with acorn flour exhibited improved sensory acceptance. The obtained results signify that the
\end{abstract}

Electronic supplementary material The online version of this article (doi:10.1007/s00217-015-2417-y) contains supplementary material, which is available to authorized users.

J. Korus $(\bowtie) \cdot$ R. Ziobro

Department of Carbohydrate Technology, University of Agriculture in Krakow, Balicka 122, 30-149 Kraków, Poland e-mail: rrkorus@cyf-kr.edu.pl

M. Witczak

Department of Engineering and Machinery for Food Industry, University of Agriculture in Krakow, Balicka 122, 30-149 Kraków, Poland

\section{Juszczak}

Department of Analysis and Evaluation of Food Quality, University of Agriculture in Krakow, Balicka 122,

30-149 Kraków, Poland application of debittered acorn flour in gluten-free baking could be useful for nutritional reasons, as it enriches bread with protein, minerals and dietary fiber, but also because of its technological effects, including structure strengthening, and sensory improvement.

Keywords Gluten-free bread · Acorn flour · Dough rheology $\cdot$ Quality $\cdot$ Texture $\cdot$ Staling

\section{Introduction}

Manufacture of bakery products for celiacs requires the use of preselected raw materials, which are free of proteins that could be harmful for these group of people [1]. The number of such ingredients and their combinations is limited, and therefore the portfolio of gluten-free bread is less variable and attractive in terms of their appearance and taste in comparison with traditional bakery products [2]. Gluten-free bread often reveals smaller volume, because of the lack of gluten network, which normally enables retention of carbon dioxide by the dough. Additionally it is often paler, less elastic, more crumbly and prone to staling process [3]. Quick staling is especially observed in the case of starch-based bread, where the absence of protein-starch interactions results in fast association of starch polymers and crystallization of retrograded starch. Moreover, in this case, water is a bound weaker, which facilitates its migration from crumb to crust, resulting in noticeable deterioration of bread quality during storage. Gluten-free bread is usually deficient in nutritionally important compounds, as compared to the products from wheat flour [1, 3, 4]. It is evident for starchy bread, which contains less protein, dietary fiber, vitamins, macro- and microelements. In the case of products based on non-wheat flours, the level of 
nutritionally important constituents strictly depends on the exact formulation. Among the ingredients of such products, one can often find flours from such cereals as maize, rice, various types of millet and sorghum [5-7], or pseudocereals: buckwheat, amaranth and quinoa. Other plant materials include: arrowroot, tapioca, sweet potato, nuts, sago, sesame and carob [8]. Legumes, namely soybean, peas and beans, are another important group, as they usually provide high levels of protein and other nutrients. The application of above-mentioned raw materials may significantly increase nutritional value of bakery products by adding protein, essential amino acids, vitamins, macro- and microelements and dietary fiber, especially if the formulations are based on starch $[1,3]$.

Acorn flour may be an interesting component of gluten-free bread, which does not need to go through a novel food approval process and would broaden the list of plant ingredients used to improve sensory and nutritional value of such bakery products. Genus Quercus belongs to family Fagaceae, which includes about 600 species of trees and shrubs growing in temperate and subtropical regions of the northern hemisphere [9]. In Europe, it is represented by several species-English or pedunculate oak Quercus robur (about $3 \%$ of forest area), sessile oak Quercus petraea and holm oak Quercus ilex (more than $2 \%$ ), downy or pubescent oak Quercus pubescens (about 1, 5 \%) [10]. Acorns were used in human nutrition in history $[11,12]$. Nowadays they are also consumed in various forms, although on a minimal scale. In some Mediterranean countries, they are regarded as edible fruit and used in ice cream and other desserts or liqueurs. In Algeria, Morocco, and some parts of USA, acorn oil is produced, while in Northern Africa, they are also consumed directly on in such products as bread, cake, and coffee (acorn bread used to be baked in Italy, while acorn coffee is still produced in some countries, such as Japan) [11, 13, 14]. Due to high variability of genus, Quercus acorns differ in chemical composition, depending on the species. It could be generally said that $31-55 \%$ of their mass is composed by starch, $2.75-8.44 \%$ protein (with advantageous amino acid composition, and high content of essential amino acids, proper especially for adults), 0.7-9 \% fat (although in some species of Quercus Erthrobalanus spp., i.e., black and red oak group, it may exceed $31 \%$ ) [11, 15-17]. Oil present in acorns has a taste comparable to olive oil and contains high levels of unsaturated fatty acids (even above $80 \%$ ), mostly oleic and linoleic acids, $10.2-65 \%$ and $17.6-49.1 \%$, respectively [15, 18]. Acorns are also a good source of minerals and biologically active compounds with an antioxidant status, which allows treating them as functional food [19, 20]. Thermal treatment of acorns reduces the level of tannins and increases the content of antioxidants which are produced by their decomposition (mostly gallic acid), which in turn significantly improves antioxidant activity of the resulting product $[20,21]$.

The aim of the study was to evaluate nutritional benefits of acorn flour application in the production of gluten-free bakery products and check its impact on rheological properties of starch-based gluten-free dough and physical properties and staling of the resulting bread.

\section{Materials and methods}

\section{Materials}

Following raw materials were used in the study: corn starch (Bezgluten, Poland), potato starch (Pepees S.A., Poland), guar gum (Lotus Gums \& Chemicals, India), pectin (Pektowin, Poland), freeze-dried yeasts Saf-instant (S.I. Lesaffre, France). Plant oil, salt and sugar were obtained from local supermarkets. Debittered acorn flour (AF) was produced by Dary Natury (Grodzisk, Poland). Its basic chemical composition was: protein $(\mathrm{N} \times 5.7)$ content by Kjeldahl method $54 \mathrm{~g} \mathrm{~kg}^{-1}$, crude fat content by Soxhlet method $52 \mathrm{~g} \mathrm{~kg}^{-1}$, starch content by polarimetric method $458 \mathrm{~g} \mathrm{~kg}^{-1}$, ash content $9 \mathrm{~g} \mathrm{~kg}^{-1}$, total, soluble and insoluble dietary fiber content by enzymatic-gravimetric method $181,36,145 \mathrm{~g} \mathrm{~kg}^{-1}$, respectively.

\section{Bread formulation}

Dough preparation was done following the method described earlier [22]. Formulation for control bread (GFB) contained $400 \mathrm{~g}$ corn starch, $100 \mathrm{~g}$ potato starch, $8.3 \mathrm{~g}$ pectin, $8.3 \mathrm{~g}$ guar gum, $25 \mathrm{~g}$ yeasts, $10 \mathrm{~g}$ sugar, $8.3 \mathrm{~g}$ salt, $15 \mathrm{~g}$ oil and $517 \mathrm{~g}$ water. In order to evaluate acorn flour as a potential ingredient of gluten-free bread, 20, 40 or $60 \%$ of total starch was replaced with it. Because of important differences in water binding between starch and acorn flour, water addition was increased by $3.2 \%$ per every $20 \%$ of included flour. Dough consistency was checked by texture analyzer TA-XT + equipped with back extrusion rig (A/BE-d 35) (Stable Micro Systems, England), and the obtained batter systems exhibited equal values of hardness during extrusion $(4 \mathrm{~N}$, at the test speed of $0.83 \mathrm{~mm} \mathrm{~s}^{-1}$, which was used as the reference for the amount of added water).

\section{Methods}

\section{Rheological properties of dough mixes}

Dough rheological properties were characterized at $25{ }^{\circ} \mathrm{C}$ using a rheometer MARS II (Thermo Haake, Germany) equipped with the system of parallel plates (diameter $35 \mathrm{~mm}$, gap $0.5 \mathrm{~mm}$ ). Dry ingredients of the dough (excluding yeast) were thoroughly mingled, water was added, and the whole 
mixture was blended using a mechanical stirrer (RW20, IKA Labortechnik, Germany) to obtain uniform mass. The samples were placed in the rheometer measuring system, and the edges were covered with paraffin oil. Dough was left for $15 \mathrm{~min}$ to relax stress and stabilize the temperature, and then the measurements were performed.

The range of linear viscoelasticity was determined by checking the dependence of storage $G^{\prime}$ and loss $G^{\prime \prime}$ moduli on the applied stress in the range of $0.1-1,000 \mathrm{~Pa}$ at a fixed frequency of $1 \mathrm{~Hz}$. Mechanical spectra were determined in the range of linear viscoelasticity at constant strain amplitude of $0.05 \%$ in the angular frequency of $1-100 \mathrm{rad} \mathrm{s}^{-1}$. The experimental data were fitted with power-law equations [23]:

$G^{\prime}(\omega)=K^{\prime} \cdot \omega^{n \prime}$

$G^{\prime \prime}(\omega)=K^{\prime \prime} \cdot \omega^{n \prime \prime}$

where $G^{\prime}$ is a storage modulus (Pa), $G^{\prime \prime}$-loss modulus (Pa), $\omega$-angular frequency $\left(\mathrm{rad} \mathrm{s}^{-1}\right)$ and $K^{\prime}, K^{\prime \prime}, n^{\prime}, n^{\prime \prime}-$ experimental constants.

\section{Bread preparation}

The ingredients of control dough, and the samples with a share of acorn flour (see Bread formulation section) were mixed for 8 min using laboratory spiral mixer SP 12 (Diosna, Germany). Then dough samples were proofed for $15 \mathrm{~min}$ at $35{ }^{\circ} \mathrm{C}$, at relative moisture $80 \%$. The dough was remixed for $1 \mathrm{~min}$ and divided into $250 \mathrm{~g}$ portions which were put in metal pans, in which final fermentation continued for $20 \mathrm{~min}$ under the above-mentioned conditions. Bread was baked for $30 \mathrm{~min}$ at $230{ }^{\circ} \mathrm{C}$ in an electric oven MIWE Condo type CO 20608 (MIWE GmbH, Germany). After removing from pans, the loaves were cooled under ambient conditions and stored for further measurement in plastic bags.

\section{Bread analysis}

Bread volume was assessed by means of laser measuring device Volscan profiler 600 (Stable Micro Systems, England). On the bases of volume and mass of loaves, specific volume was calculated. Bread slices $(1 \mathrm{~cm}$ width) taken from the center of the loaf were used for image analysis. They were scanned by means of flatbed scanner Plustek S-12 (Plustek, Taiwan). Then the images were analyzed with the help of ImageJ software v. $1.44 \mathrm{c}$ (NIH, USA) [24], evaluating porosity, i.e., area of gas cells divided by area of bread slice, cell density, i.e., number of pores per $1 \mathrm{~cm}^{2}$, and percentage of pores $>5 \mathrm{~mm}$ [25]. Color of bread crumb was measured in CIE $L^{*} a^{*} b^{*}$ system by reflectance method using Color i5 spectrometer (X-Rite, USA) set for the following parameters: measuring geometry $\mathrm{d} / 8$, illuminant D65, observer $10^{\circ}$, slit width $25 \mathrm{~mm}$.
Sensory analysis of bread was performed by a panel consisting of twelve trained persons with a checked sensory sensibility (according to Polish Standard PN-ISO 8586-1:1996) [26]. Analyses were done under the conditions described by Polish Standard PN-ISO 8589:2010 [27], using the method of acceptance analysis, in which the pre-coded samples were given scores from a nine-point scale (1—extremely like; 9-extremely dislike). The panelists considered the following quality attributes: appearance, structure and porosity, color, smell and taste.

Texture profile analysis of bread crumb was performed, using texture analyzer TA-XT2plus (Stable Micro Systems, England), according to standard program, at the compression rate $5 \mathrm{~mm} / \mathrm{s}$. Sample of bread crumb, taken from the center of the loaf with a height $2 \mathrm{~cm}$, was pressed to reach $50 \%$ deformation by a P/20 aluminum cylinder probe with a diameter $2 \mathrm{~cm}$, in two cycles with a 5-s delay. The resulting hardness, springiness and cohesiveness of the crumb were used as indicators of textural changes during storage. The calculations were performed using the attached software Texture Exponent (Stable Micro Systems, England). The analyses were performed after 2, 24 and $48 \mathrm{~h}$ after baking.

Thermal properties of gluten-free bread crumb were characterized by means of differential scanning calorimeter DSC 204F1 Phoenix (Netzsch, Germany). The calorimeter was calibrated by indium standard. The analyses were performed after 2, 24 and $48 \mathrm{~h}$ after baking. Crumb samples $(\sim 15 \mathrm{mg})$ were closed hermetically in aluminum pans and heated in the calorimeter from 25 to $100{ }^{\circ} \mathrm{C}$ at a rate of $10{ }^{\circ} \mathrm{C} \mathrm{min}^{-1}$. Empty aluminum pan was used as reference. Temperatures and enthalpy of thermal transitions were determined with the use of instrument's software Proteus Analysis (Netzsch, Germany). Enthalpy values were expressed as $\mathrm{J} \mathrm{g}^{-1} \mathrm{db}$.

\section{Statistical analyses}

In order to establish the statistical differences between means, the data were treated by one-factor analysis of variance, and the averages were compared with the Duncan test at significance level 0.05 . The influence of selected factors was analyzed with the use of two-factorial analysis of variance. All calculations were performed with statistical software package Statistica 9.0 (StatSoft Inc., USA).

\section{Results and discussion}

\section{Rheological characteristics of dough}

The analysis of viscoelastic properties of the dough allows evaluating the influence of additives, and other modifications of recipe, on rheological properties of the dough. 

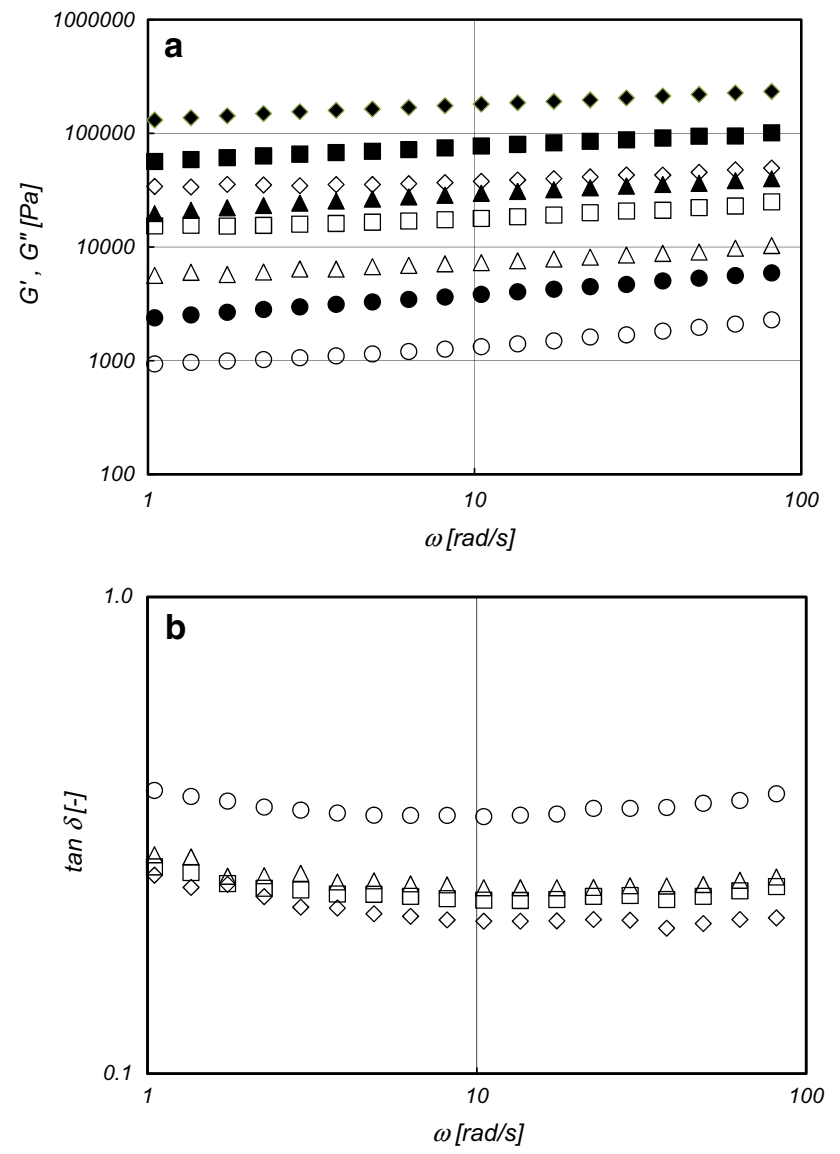

Fig. 1 Mechanical spectra and tangent of phase shift of control dough and samples with acorn flour: circle Control GFB, triangle $20 \% \mathrm{AF}$, square $40 \mathrm{AF} \%$, diamond $60 \% \mathrm{AF} ; G^{\prime}$ filled symbols, $G^{\prime \prime}$ empty symbols

Figure 1a demonstrates mechanical spectra of control dough and samples in which part of starch was replaced with acorn flour. Figure $1 \mathrm{~b}$ shows the respective changes in phase shift tangent at varied angular frequency. All dough samples exhibited the domination of elastic properties over viscous ones $\left(G^{\prime}>G^{\prime \prime}\right)$ in the whole applied range of angular frequencies. It was confirmed by the values of phase shift tangent $\tan \delta<1$ (Fig. 1b). Relative position of the curves representing moduli and the values of $\tan \delta>0.1$ indicate properties typical for weak gels. It confirms earlier observations made for gluten-free dough based on starch [23, 28]. Partial replacement of starch with acorn flour resulted in a significant increase in both moduli (Fig. 1a), which was proportional to the extent of this replacement. This was accompanied by the drop in the values of phase shift tangent (Fig. 1b), which was also corresponding to the amount of acorn flour used for starch replacement, and reflected by the constants of power-law equations used to describe experimental data (Table 1). The values of $K^{\prime}$ and $K^{\prime \prime}$ parameters increased significantly with rising level of acorn flour in the dough, which corresponds to the increase in $G^{\prime}$ and $G^{\prime \prime}$. A parallel drop observed in the case of $n^{\prime}$ and $n$ " parameters, which diminished with added acorn flour, indicates lesser dependence of moduli on angular frequency. The values of phase shift tangent at $\delta=1 \mathrm{rad} / \mathrm{s}$ collected in Table 1 were significantly lower for samples with acorn flour in comparison with control dough. Although they indicate a lack of statistical variance at $1 \mathrm{~Hz}$, at the same time, their values at higher frequencies significantly differ, indicating that growing share of acorn flour in the dough results in its greater elasticity and smaller susceptibility to applied stress. One of the factors causing such changes in rheological characteristics of the dough is water absorption capacity, which is significantly different for starch and acorn flour. The flour contains significant levels of fiber, which is characterized by high water absorption. The increase in an amount of absorbed water results in a greater volume of hydrated molecules, which are more likely to interact under the applied stress. Another factor which could influence rheological characteristics of the dough with acorn flour is the presence of other nonstarch structure-forming components. The applied flour contains approximately $5 \%$ protein and other organic molecules classified as soluble dietary fiber. All these components may interact with hydrocolloids present in a dough

Table 1 Parameters of the power-law functions describing dependence of storage and loss moduli on angular frequency of gluten-free dough

\begin{tabular}{llllll}
\hline Parameter & Control GFB & $20 \% \mathrm{AF}$ & $40 \% \mathrm{AF}$ & $60 \%$ AF & One-way ANOVA- $p$ \\
\hline$K^{\prime}\left(\mathrm{Pa} \mathrm{s}^{n^{\prime}}\right)$ & $2363.0 \pm 18.2^{\mathrm{a}}$ & $20583.3 \pm 1506.8^{\mathrm{b}}$ & $59386.7 \pm 3776.3^{\mathrm{c}}$ & $133233.3 \pm 3008.9^{\mathrm{d}}$ & $<0.001$ \\
$n^{\prime}$ & $0.209 \pm 0.004^{\mathrm{a}}$ & $0.152 \pm 0.006^{\mathrm{b}}$ & $0.127 \pm 0.006^{\mathrm{c}}$ & $0.128 \pm 0.001^{\mathrm{c}}$ & $<0.001$ \\
$r^{2}>$ & 0.999 & 0.988 & 0.998 & 0.998 & - \\
$K^{\prime \prime}\left(\mathrm{Pa} \mathrm{s}^{n^{\prime \prime}}\right)$ & $815.2 \pm 20.9^{\mathrm{a}}$ & $5343.3 \pm 435.7^{\mathrm{b}}$ & $14316.7 \pm 188.8^{\mathrm{c}}$ & $31553.3 \pm 593.4^{\mathrm{d}}$ & $<0.001$ \\
$n^{\prime \prime}$ & $0.229 \pm 0.002^{\mathrm{a}}$ & $0.145 \pm 0.006^{\mathrm{b}}$ & $0.120 \pm 0.005^{\mathrm{c}}$ & $0.095 \pm 0.005^{\mathrm{d}}$ & $<0.001$ \\
$r^{2}>$ & 0.979 & 0.912 & 0.907 & 0.923 & - \\
$\tan \delta{\mathrm{at} 1 \mathrm{rad} \mathrm{s}^{-1}}^{0.393 \pm 0.006^{\mathrm{a}}}$ & $0.288 \pm 0.056^{\mathrm{b}}$ & $0.272 \pm 0.020^{\mathrm{b}}$ & $0.261 \pm 0.014^{\mathrm{b}}$ & 0.003 & \\
\hline
\end{tabular}

Mean value of three replication \pm standard deviation

Mean values signed with the same letters in particular rows do not differ significantly at 0.05 level of confidence 
mix (guar gum and pectin) strengthening structure of the dough and further bread crumb.

\section{Chemical and physical characteristics of bread}

Basic parameters characterizing analyzed bread are collected in Table 2. Partial replacement of starch with acorn flour caused a significant increase in the content of protein, fat and dietary fiber, and a decrease in total carbohydrate content in comparison with control bread. The extent of these changes was parallel with the level of replacement which seems obvious. The application of acorn flour resulted in an increase in protein content by $37-105 \%$, which seems to be especially important, taking into account protein deficiency in gluten-free products. The increase in fat level varied between 24 and $72 \%$, and in dietary fiber-76-220\%, while a decrease in carbohydrate content ranged between 5 and $13 \%$. The changes were the consequence of chemical composition of acorn flour, which contained more analyzed components than starch, with the exception of total carbohydrates. In comparison with wheat flour, acorn flour contains less protein (54 vs. $80-134 \mathrm{~g} \mathrm{~kg}^{-1}$ ) and starch (458 vs. $\left.618-739 \mathrm{~g} \mathrm{~kg}^{-1}\right)$, but more fat (52 vs. 13-22) and total fiber (181 vs. $38 \mathrm{~g} \mathrm{~kg}^{-1}$ ), including its soluble (36 vs. $9 \mathrm{~g} \mathrm{~kg}^{-1}$ ) and insoluble (145 vs. $29 \mathrm{~g} \mathrm{~kg}^{-1}$ ) fractions [29-32]. The results could hardly be compared with wheat bread, as its composition significantly depends on applied formulations which differ significantly among authors. However, it could be observed that gluten-free bread with acorn flour contained less protein $\left(16,7-25\right.$ vs. $\left.73,7-78,9 \mathrm{~g} \mathrm{~kg}^{-1}\right)$ and total carbohydrates
(400-439 vs. $532-735 \mathrm{~g} \mathrm{~kg}^{-1}$ ) than wheat bread, while the level of fat $\left(23,33-32,40\right.$ vs. $\left.5,6-7,9 \mathrm{~g} \mathrm{~kg}^{-1}\right)$ and dietary fiber $\left(47,14-85,49\right.$ vs. $\left.11,5-17,6 \mathrm{~g} \mathrm{~kg}^{-1}\right)$ was elevated in this case [33-35].

In most cases the application of acorn flour significantly influenced color and other physical characteristics of the loaves. Significant increase in bread volume could be observed, when the level of starch replacement with acorn flour was the lowest, while larger amounts of the flour caused a decrease in bread volume. This suggests that limited amounts of water-binding substances (e.g., protein and fiber) present in acorn flour positively influence structure and gas retention capacity of rising dough, which results in greater volume. However, too strong dough, obtained at higher levels of those substances, due to increased water binding and/or changes in density, could restrain proofing process. The sample with $20 \%$ addition of acorn flour was characterized with the highest porosity and largest number of pores larger than $5 \mathrm{~mm}$ (Table 2; Online Resource 1). Although porosity of bread with higher amounts of acorn flour was smaller, it still over-passed the value for control sample. Substantial (40 and $60 \%$ ) share of acorn flour caused decrease in large pores (larger than $5 \mathrm{~mm}$ ) to values comparable or lower to as those observed for control. The smallest number of pores per volume was found for the sample with $20 \%$ addition of acorn flour, which was due to its highest volume and porosity. The values of this parameter measured for two other samples with acorn flour were also smaller in comparison with control. Improvement of structure of gluten-free bread, reflected also by its greater volume, was earlier found after addition of soy flour,

Table 2 Chemical and physical characteristics of gluten-free bread

\begin{tabular}{|c|c|c|c|c|c|}
\hline Parameter & Control GFB & $20 \% \mathrm{AF}$ & $40 \% \mathrm{AF}$ & $60 \% \mathrm{AF}$ & One-way ANOVA- $p$ \\
\hline $\operatorname{Protein}^{1}\left(\mathrm{~g} \mathrm{~kg}^{-1}\right)$ & $12.20 \pm 0.75^{\mathrm{a}}$ & $16.70 \pm 0.95^{\mathrm{b}}$ & $20.77 \pm 0.87^{\mathrm{c}}$ & $25.01 \pm 0.76^{\mathrm{d}}$ & $<0.001$ \\
\hline $\mathrm{Fat}^{1}\left(\mathrm{~g} \mathrm{~kg}^{-1}\right)$ & $18.87 \pm 0.95^{\mathrm{a}}$ & $23.33 \pm 0.87^{b}$ & $28.05 \pm 1.08^{c}$ & $32.40 \pm 0.95^{\mathrm{d}}$ & $<0.001$ \\
\hline Carbohydrates $^{1}\left(\mathrm{~g} \mathrm{~kg}^{-1}\right)$ & $461 \pm 11^{\mathrm{c}}$ & $439 \pm 10^{\mathrm{b}}$ & $419 \pm 10^{\mathrm{a}}$ & $400 \pm 11^{\mathrm{a}}$ & $<0.001$ \\
\hline Dietary fiber ${ }^{1}\left(\mathrm{~g} \mathrm{~kg}^{-1}\right)$ & $26.73 \pm 0.97^{\mathrm{a}}$ & $47.14 \pm 0.87^{\mathrm{b}}$ & $66.25 \pm 1.07^{\mathrm{c}}$ & $85.49 \pm 0.96^{\mathrm{d}}$ & $<0.001$ \\
\hline Volume $^{2}\left(\mathrm{~cm}^{3}\right)$ & $573.0 \pm 4.77^{\mathrm{c}}$ & $622.9 \pm 13.62^{\mathrm{d}}$ & $520.1 \pm 12.43^{\mathrm{b}}$ & $407.0 \pm 7.92^{\mathrm{a}}$ & $<0.001$ \\
\hline Weight $^{2}(g)$ & $198.3 \pm 1.37^{\mathrm{b}}$ & $195.2 \pm 1.17^{\mathrm{a}}$ & $199.8 \pm 1.72^{\mathrm{bc}}$ & $202.7 \pm 4.59^{c}$ & $<0.001$ \\
\hline Specific volume ${ }^{2}\left(\mathrm{~cm}^{3} \mathrm{~g}^{-1}\right)$ & $2.89 \pm 0.034^{\mathrm{c}}$ & $3.19 \pm 0.069^{\mathrm{d}}$ & $2.60 \pm 0.078^{b}$ & $2.01 \pm 0.023^{\mathrm{a}}$ & $<0.001$ \\
\hline Porosity $^{2}$ & $0.413 \pm 0.015^{\mathrm{a}}$ & $0.511 \pm 0.006^{\mathrm{c}}$ & $0.498 \pm 0.008^{\mathrm{b}}$ & $0.493 \pm 0.016^{\mathrm{b}}$ & $<0.001$ \\
\hline Cell density ${ }^{2}\left(\mathrm{~cm}^{-2}\right)$ & $18.3 \pm 2.28^{\mathrm{d}}$ & $7.7 \pm 0.26^{\mathrm{a}}$ & $9.7 \pm 0.56^{\mathrm{b}}$ & $11.3 \pm 1.46^{\mathrm{c}}$ & $<0.001$ \\
\hline Percentage of pores $>5 \mathrm{~mm}^{2}$ & $0.527 \pm 0.035^{\mathrm{b}}$ & $0.600 \pm 0.026^{\mathrm{c}}$ & $0.511 \pm 0.024^{\mathrm{b}}$ & $0.487 \pm 0.025^{\mathrm{a}}$ & $<0.001$ \\
\hline$L^{* 3}$ & $76.9 \pm 0.97^{\mathrm{a}}$ & $44.8 \pm 1.39^{\mathrm{b}}$ & $38.7 \pm 1.01^{\mathrm{c}}$ & $37.2 \pm 0.35^{\mathrm{d}}$ & $<0.001$ \\
\hline$a^{* 3}$ & $-1.19 \pm 0.13^{\mathrm{a}}$ & $7.14 \pm 0.41^{\mathrm{c}}$ & $6.58 \pm 0.43^{b}$ & $7.12 \pm 0.12^{\mathrm{c}}$ & $<0.001$ \\
\hline$b^{* 3}$ & $13.4 \pm 0.29^{\mathrm{a}}$ & $19.8 \pm 0.45^{\mathrm{c}}$ & $17.1 \pm 0.77^{\mathrm{b}}$ & $16.4 \pm 0.81^{\mathrm{b}}$ & $<0.001$ \\
\hline
\end{tabular}

\footnotetext{
${ }^{1}$ Mean value of three replication \pm standard deviation

${ }^{2}$ Mean value of six replication \pm standard deviation

${ }^{3}$ Mean value of five replication \pm standard deviation. Mean values signed with the same letters in particular rows do not differ significantly at 0.05 level of confidence
} 
which was a source of structure-forming protein and active enzymes [36]. Also Miñarro et al. [37] received gluten-free bread with improved quality (including sensory parameters) after application of chickpea flour.

Color of a product significantly affects its consumer acceptance. Spectrophotometric measurement of color may be precisely expressed in a three-dimensional color space, which corresponds to its perception by human eye. The results acquired for bread crumb of control sample and products supplemented with acorn flour are represented in Table 2. The highest value of $L^{*}$ corresponding to lightness was obtained for control sample. Such a high lightness of gluten-free bread is especially typical for bakery products based on starch [38]. Application of acorn flour significantly changed this value, decreasing $L^{*}$ in a way proportional to the level of supplementation. The involvement of acorn flour in bread formulation had also an influence on other color parameters. In the case of $a^{*}$, which was negative for control, the addition of acorn flour resulted in its change to positive values, signifying predominance of red over green in bread color. However, the differences between samples with varying levels of acorn flour were small. In all cases, the value of $b^{*}$ was positive, which corresponds to that yellow was more intensive than blue both in control bread and acorn flour supplemented samples. $20 \%$ replacement of starch with acorn flour caused an increase in crumb yellowness, while further additions caused a slight drop in this value. Instrumental analysis of crumb color revealed a significant influence of applied acorn flour on bread crumb appearance. It seems that a reduction of lightness could be most beneficial in terms of sensory attractiveness.

\section{Crumb texture}

Bread texture is an important quality parameter. Because of relatively neutral taste of such bakery products, it could often be taken as a key factor for bread acceptance. It is also the most obvious indicator of the changes, which occur in crumb structure during storage due to the loss of moisture, starch retrogradation and other physicochemical interactions between bread constituents. Supplementation of glutenfree bread with various types of plant flour could modify these phenomena and in this way affect crumb texture. The changes in texture of analyzed samples during storage are shown in Fig. 2. In most cases bread hardness increased significantly over the analyzed period. However, an addition of acorn flour modified the extent of these changes. Two-way analysis of variance proved statistically significant influence of supplementation level $(p<0.001)$, time of storage $(p<0.001)$ and interaction of these two factors $(p<0.001)$. The replacement of starch with acorn flour at $20 \%$ level had a beneficial effect on hardness over storage. On the day of baking, the loaves with 20 and $40 \%$ were comparably firm
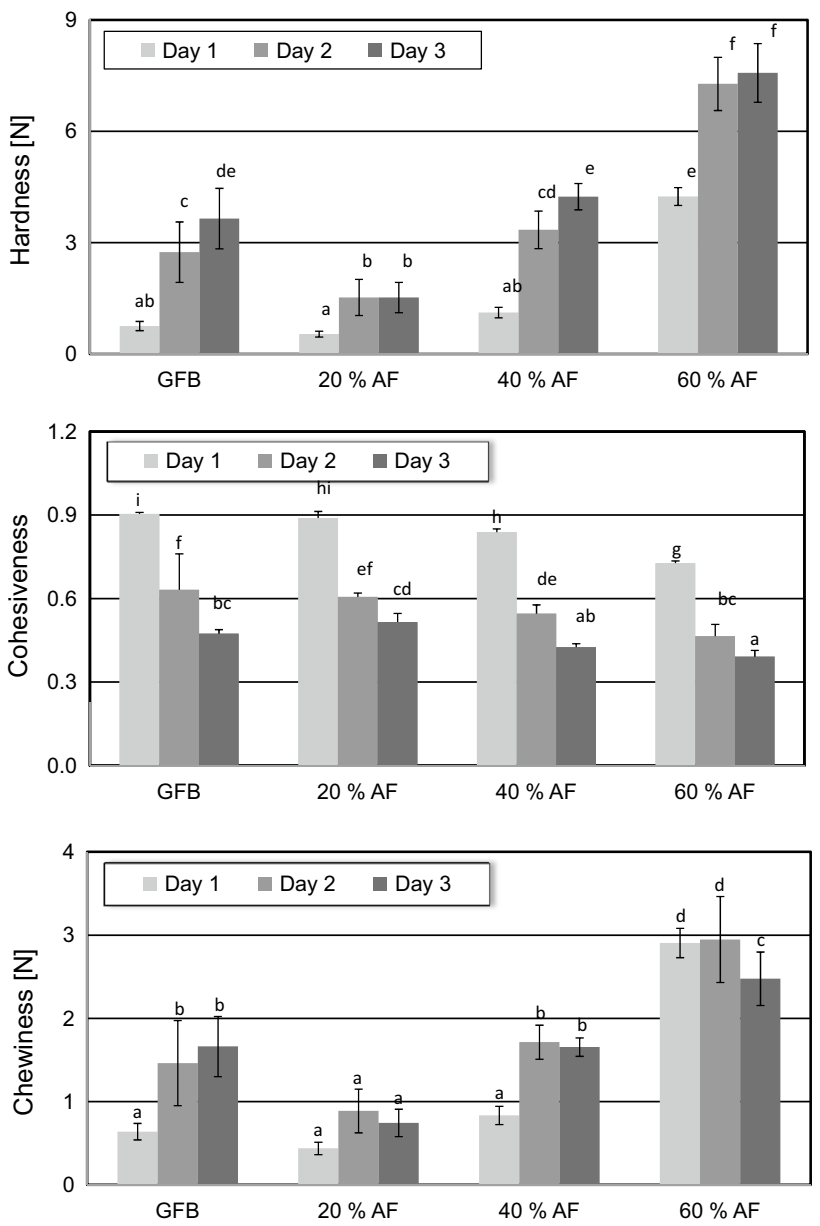

Fig. 2 Texture parameters of gluten-free bread

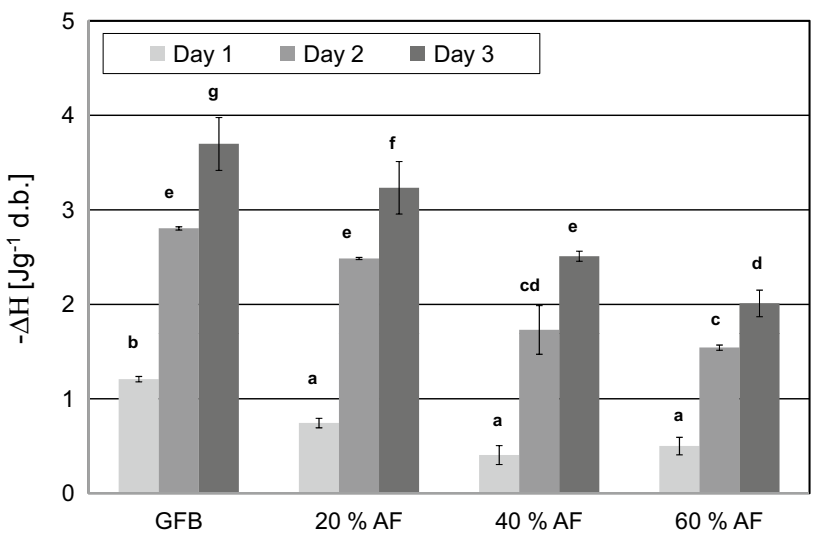

Fig. 3 Enthalpy of amylopectin melting after retrogradation of gluten-free bread crumb during storage

as a control sample. On the following days, the sample with $20 \%$ addition of acorn flour was significantly softer than all other samples. It was also observed that in this case, the changes in crumb hardness between 2 and 3 days of storage 
were not statistically significant. In the case of bread with $40 \%$ acorn flour, the increase in hardness over storage was comparable to control. This type of bread revealed best consumer acceptance in terms of structure and porosity (Fig. 3). Bread with $60 \%$ was much harder than all other samples on the day of baking, and staled so quickly, that after two days of storage was more than twice as hard as other samples. The influence of non-cereal flours on gluten-free bread was earlier reported by Alvarez-Jubete et al. [39], who observed a decrease after supplementation of the dough with buckwheat and quinoa flours. According to these authors, the reduction of crumb hardness is caused by the incorporation of natural emulsifiers, present in such flours. It could be also observed that there is a correlation between bread volume and crumb hardness [40], which has been confirmed by the above data, as the bread with the highest volume, which contained $20 \%$ acorn flour (Table 2) had the softest crumb (Fig. 2), and one with the lowest volume, containing $60 \%$ acorn flour, was the hardest (Table 2). Springiness (data not shown) was not variable in a statistically significant way, and two-way ANOVA proved lack of the influence of addition level and storage time, as well as interaction of these two factors, on its values.

Crumb cohesiveness was the next analyzed texture parameter (Fig. 2). Although two-way analysis of variance proved a significant influence of addition level $(p<0.001)$ and storage time on this parameter, the values did not differ much between samples. Supplementation of bread with $20 \%$ acorn flour had no statistically significant influence on its cohesiveness in comparison with control. Only at larger quantities of the additive, its value was decreased in a statistically significant way, especially on the second and third day of storage.

Also chewiness was influenced by the addition level and storage time as well as their interaction in a statistically significant way $(p<0.001)$. In general, on the day of baking, the values of chewiness for bread containing 20 and $40 \%$ share of acorn flour were on the same level as control. In case of $20 \%$ addition, the increase in chewiness after storage was not statistically significant, while for bread with $40 \%$ acorn flour and control it could be observed only on the second day of storage. In the case of a sample with $60 \%$ acorn flour, the pattern was slightly different. The initial value of chewiness was in this case significantly higher than for other samples on the day of baking and on the second day of storage. The drop was observed on the third day of storage, which could be connected to a decrease in crumb springiness observed for this sample at the end of storage period.

\section{Thermal properties}

Bread crumb thermograms registered during heating exhibit a peak referring to swelling of retrograded amylopectin.
The range of temperatures for this transition varied between 49.2 and $55.0{ }^{\circ} \mathrm{C}$ for onset, $59.6-63.2{ }^{\circ} \mathrm{C}$ for peak maximum and from 75.0 to $80.0{ }^{\circ} \mathrm{C}$ for its end (data not shown). Basing on the results of applied two-way ANOVA, it was, however, found that neither the level, time of storage, nor interaction of both these factors had statistically important effects on these values. The influence was only observed for transition enthalpy $(p<0.001)$, which could be seen on Fig. 4. For fresh bread (on the day of baking), the addition of acorn flour, at all applied levels, caused a decrease in enthalpy value in comparison to control, although the exact level of this addition was not statistically important. Significant reduction of melting enthalpy in comparison with control could also be observed on the second day of storage for samples with 40 and $60 \%$ share of acorn flour; however, the difference between these values was not statistically important. On the third day of baking, the differences between enthalpies measured for samples with varying levels of acorn flour were observed, and a decrease in these values was proportional to applied replacement level. The reduction in recrystallisation enthalpy of amylopectin could be caused by two factors. Partial replacement of starch with acorn flour causes a decrease of total amount of amylopectin in a system, and an addition of acorn flour results in an introduction of new structure-forming substances, which could interact with amylopectin and retard its recrystallisation. However, staling is a complex process, which involves recrystallization of amylopectin only as one of many factors; thus, crumb hardening should not be identified with amylopectin retrogradation.

\section{Sensory assessment of bread}

The results of sensory assessment of analyzed bread are represented on Fig. 4. Most parameters were positively

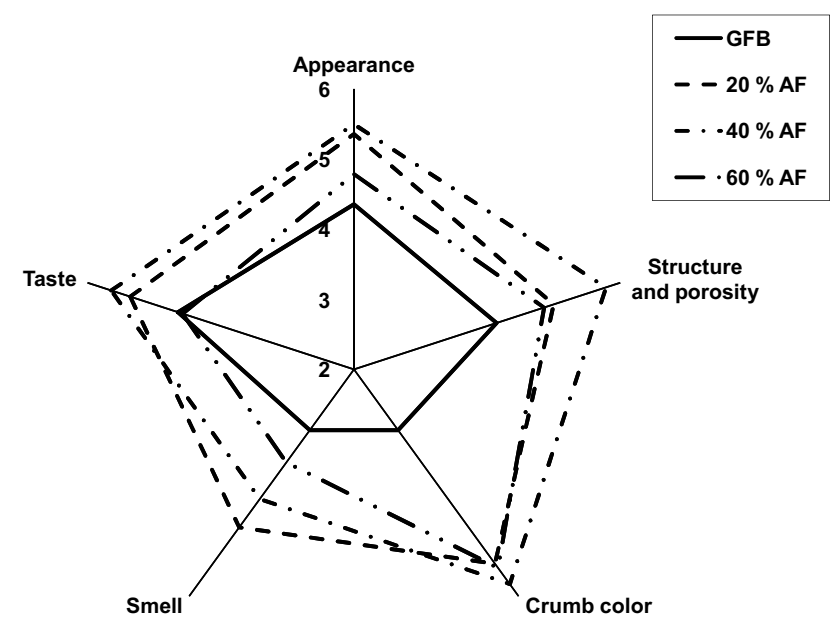

Fig. 4 Results of sensory acceptance of gluten-free bread 
influenced by the application of acorn flour, showing greater consumer acceptance than the control sample. The replacement of $20-40 \%$ of starch in bread recipe with acorn flour had a beneficial influence on bread appearance. Further addition of the flour $(60 \%)$ caused a decrease in this parameter, but the sample received better scores than control. Taking into account structure and porosity, the worst scores were given to control sample, while bread with $40 \%$ share of acorn flour was most accepted. It revealed medium porosity, pore density and percentage of pores larger than $5 \mathrm{~mm}$ (Table 2). Color of crumb was much more acceptable in the case of bread supplemented with acorn flour in comparison with control, most probably due to reduced paleness (Table 2), which is commonly regarded as an indicator of highly refined, less healthy products. Smell was also more acceptable for supplemented loaves than for control, but in this case, the acceptability observed at $20 \%$ addition level was much higher than for all other samples. Bread with $60 \%$ acorn flour and control were the least acceptable in terms of their taste, which is probably due to easily identified, odd flavor typical either for hydrocolloids, or acorns, but not bread. Both other samples were much better accepted, which proves that limited addition (up to $40 \%$ ) of acorn flour positively impacts sensory parameters and overall acceptance of gluten-free bread.

\section{Conclusions}

Partial replacement of starch in gluten-free formulation by debittered acorn flour had significant influence on rheological properties of respective bread dough. It was demonstrated by strengthening of dough structure, registered as an increase in values of storage and loss moduli and drop in phase shift tangent. Supplementation of bread with acorn flour at the level of $20 \%$ had positive impact on bread volume and physical properties of the crumb. Higher levels of starch replacement cause a reduction of loaf volume. Introduction of acorn flour significantly diminished crumb paleness, which was reflected by better sensory scores for bread color. Overall sensory acceptance of bread with acorn flour was improved, especially when it replaced 20 or $40 \%$ of starch in formulation. Addition of acorn flour resulted in slower retrogradation of amylopectin during storage, which up to $20 \%$ was also accompanied by retardation of bread staling. Above this level, crumb hardening was more influenced by other factors.

The above results signify that the application of debittered acorn flour in gluten-free baking could be useful for nutritional reasons, as it enriches bread with protein, minerals and dietary fiber, but also because of its technological effects, including structure strengthening, and sensory improvement. Although acorn flour is more expensive than starch, its use in gluten-free formulations would have only a slight influence on bread price, as costs of raw materials are approximately $30 \%$ of total costs in bread production, and the advised level of replacement does not exceed $40 \%$.

\section{Conflict of interest None}

Compliance with Ethics Requirements This article does not contain any studies with human or animal subjects.

Open Access This article is distributed under the terms of the Creative Commons Attribution License which permits any use, distribution, and reproduction in any medium, provided the original author(s) and the source are credited.

\section{References}

1. O'Shea N, Arendt E, Gallagher E (2014) State of the art in gluten-free research. J Food Sci 79(6):R1067-R1076

2. de Morais EC, Cruz AG, Bolini HMA (2013) Gluten-free bread: multiple time-intensity analysis, physical characterisation and acceptance test. Int J Food Sci Technol 48(10):2176-2184

3. Matos ME, Rosell CM (2014) Understanding gluten-free dough for reaching breads with physical quality and nutritional balance. J Sci Food Agric. doi:10.1002/jsfa.6732

4. Matos Segura ME, Rosell CM (2011) Chemical composition and starch digestibility of different gluten-free breads. Plant Foods Hum Nutr 66(3):224-230

5. Torbica A, Hadnađev M, Dapčević T (2010) Rheological, textural and sensory properties of gluten-free bread formulations based on rice and buckwheat flour. Food Hydrocoll 24(6-7):626-632

6. Matos ME, Rosell CM (2013) Quality indicators of rice-based gluten-free bread-like products: relationships between dough rheology and quality characteristics. Food Bioprocess Technol 6(9):2331-2341

7. Pongjaruvat W, Methacanon P, Seetapan N, Fuongfuchat A, Gamonpilas C (2014) Influence of pregelatinised tapioca starch and transglutaminase on dough rheology and quality of glutenfree jasmine rice breads. Food Hydrocoll 36:143-150

8. Tsatsaragkou K, Gounaropoulos G, Mandala I (2014) Development of gluten free bread containing carob flour and resistant starch. LWT-Food Sci Technol 58(1):124-129

9. Jawarneh MS, Brake MH, Muhaidat R, Migdadi HM, Lahham JN, El-Oqlah AA (2013) Characterization of Quercus species distributed in Jordan using morphological and molecular markers. Afr J Biotechnol 12(12):1326-1334

10. Köble R, Seufert G (2001) Novel maps for forest tree species in Europe. Monitoring Agricultural Resources (MARS). ftp://mars. jrc.ec.europa.eu/Afoludata/Public/DS66/description_tree_species_maps.pdf. Accessed 2 September 2014

11. Al-Rousan WM, Ajo RY, Al-Ismail KM, Attlee A, Shaker RR, Osaili TM (2013) Characterization of acorn fruit oils extracted from selected mediterranean Quercus species. Grasas y Aceites 64(5):554-560

12. Šálková T, Divišová M, Kadochová Š, Beneš J, Delawská K, Kadlčková E, Němečková L, Pokorná K, Voska V, Žemličková A (2011) Acorns as a food resource. An experiment with acorn preparation and taste. Interdisciplinaria Archaeologica, Natural Sciences in Archaeology II (1):9-14

13. Pignone D, Laghetti G (2010) On sweet acorn (Quercus spp.) cake tradition in Italian cultural and ethnic islands. Genet Resour Crop Evol 57(8):1261-1266 
14. Pinna C (2013) Acorn bread: a traditional food of the past in Sardinia (Italy). J Cult Herit 14(3):S71-S74

15. Charef M, Yousfi M, Saidi M, Stocker P (2008) Determination of the fatty acid composition of acorn (Quercus), Pistacia lentiscus seeds growing in Algeria. J Am Oil Chem Soc 85(10):921-924

16. Correia PR, Beirão-da-Costa ML (2012) Starch isolation from chestnut and acorn flours through alkaline and enzymatic methods. Food Bioprod Process 90(2):309-316

17. Özcan $\mathrm{T}$ (2006) Total protein and amino acid compositions in the acorns of Turkish Quercus L. taxa. Genet Resour Crop Evol 53(2):419-429

18. Özcan T (2007) Characterization of Turkish Quercus L. taxa based on fatty acid compositions of the acorns. J Am Oil Chem Soc 84(7):653-662

19. Özcan T, Bayçu G (2005) Some elemental concentrations in the acorns of Turkish Quercus L. (Fagaceae) taxa. Pak J Bot 37(2):361-371

20. Rakić S, Povrenović D, Tešević V, Simić M, Maletić R (2006) Oak acorn, polyphenols and antioxidant activity in functional food. J Food Eng 74(3):416-423

21. Rakić S, Petrović S, Kukić J, Jadranin M, Tešević V, Povrenović D, Šiler-Marinković S (2007) Influence of thermal treatment on phenolic compounds and antioxidant properties of oak acorns from Serbia. Food Chem 104(2):830-834

22. Korus J, Witczak M, Ziobro R, Juszczak L (2009) The impact of resistant starch on characteristics of gluten-free dough and bread. Food Hydrocoll 23(3):988-995

23. Witczak M, Korus J, Ziobro R, Juszczak L (2010) The effects of maltodextrins on gluten-free dough and quality of bread. J Food Eng 96(2):258-265

24. Abramoff MD, Magelhaes PJ, Ram SJ (2004) Image processing with ImageJ. Biophotonics Int 11:36-42

25. Gonzales-Barron U, Butler F (2006) A comparison of seven thresholding techniques with the k-means clustering algorithm for measurement of bread-crumb features by digital image analysis. J Food Eng 74(2):268-278

26. PKN (1996) Sensory analysis-general guidance for selection, training and monitoring of assessors-Part 1: Selected assessors. Polish Committee for Standardization, Warsaw

27. PKN (2010) Sensory analysis—a general guidance for the design of test rooms. Polish Committee for Standardization, Warsaw

28. Juszczak L, Witczak T, Ziobro R, Korus J, Cieślik E, Witczak M (2012) Effect of inulin on rheological and thermal properties of gluten-free dough. Carbohyd Polym 90(1):353-360
29. Indrani D, Rao G (2000) Effect of chemical composition of wheat flour and functional properties of dough on the quality of south Indian parotta. Food Res Int 33(10):875-881

30. Prabhasankar P, Haridas Rao P (2001) Effect of different milling methods on chemical composition of whole wheat flour. Eur Food Res Technol 213(6):465-469

31. Yadav DN, Rajan A, Sharma GK, Bawa AS (2010) Effect of fiber incorporation on rheological and chapati making quality of wheat flour. J Food Sci Technol 47(2):166-173

32. Kumar P, Yadava RK, Gollen B, Kumar S, Verma RK, Yadav S (2011) Nutritional contents and medicinal properties of wheat: a review. Life Sci Med Res 20:1-10

33. Marques C, D'auria L, Cani PD, Baccelli C, Rozenberg R, Ruibal-Mendieta NL, Petitjean G, Delacroix DL, QuetinLeclercq J, Habib-Jiwan J, Meurens M, Delzenne NM (2007) Comparison of glycemic index of spelt and wheat bread in human volunteers. Food Chem 100(3):1265-1271

34. Collar C, Angioloni A (2014) Nutritional and functional performance of high $\beta$-glucan barley flours in breadmaking: mixed breads versus wheat breads. Eur Food Res Technol 238(3):459-469

35. Ngozi AA (2014) Effect of whole wheat flour on the quality of wheat-baked bread. Glob J Food Sci Technol 2(3):127-133

36. Ribotta PD, Ausar SF, Morcillo MH, Pérez GT, Beltramo DM, León AE (2004) Production of gluten-free bread using soybean flour. J Sci Food Agric 84(14):1969-1974

37. Miñarro B, Albanell E, Aguilar N, Guamis B, Capellas M (2012) Effect of legume flours on baking characteristics of gluten-free bread. J Cereal Sci 56(2):476-481

38. Korus J, Juszczak L, Ziobro R, Witczak M, Grzelak K, Sójka M (2012) Defatted strawberry and blackcurrant seeds as functional ingredients of gluten-free bread. J Texture Stud 43(1):29-39

39. Alvarez-Jubete L, Auty M, Arendt EK, Gallagher E (2010) Baking properties and microstructure of pseudocereal flours in gluten-free bread formulations. Eur Food Res Technol 230(3):437-445

40. Moore MM, Heinbockel M, Dockery P, Ulmer HM, Arendt EK (2006) Network formation in gluten-free bread with application of transglutaminase. Cereal Chem 83(1):28-36 